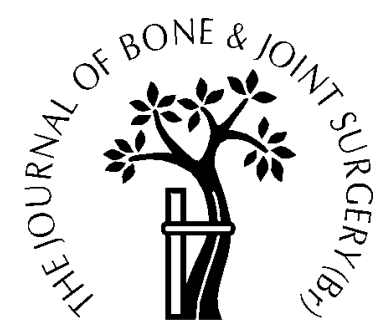

\title{
Treatment for displaced intracapsular fracture of the proximal femur
}

\author{
A PROSPECTIVE, RANDOMISED TRIAL IN PATIENTS AGED 65 \\ TO 79 YEARS
}

J. N. S. Davison, S. J. Calder, G. H. Anderson, G. Ward, C. Jagger, W. M. Harper, P. J. Gregg

From Leicester Royal Infirmary, England

$\mathbf{W}^{\mathrm{e}}$ performed a prospective, randomised trial comparing three treatments for displaced intracapsular fractures of the hip in 280 patients aged 65 to 79 years.

The mean patient survival was significantly higher in the group undergoing reduction and internal fixation (79 months) compared with that with a cemented Thompson hemiarthroplasty or a cemented Monk bipolar hemiarthroplasty (61 months and 68 months, respectively). After three years, 32 of 93 patients $(34.4 \%)$ who had undergone fixation had local complications, necessitating further intervention in 28 $(30 \%)$. There were no significant differences in the functional outcome in survivors, who were reviewed annually to five years.

Either reduction and internal fixation or cemented hemiarthroplasty may be offered as alternative treatments for a displaced intracapsular fracture in a mobile and mentally competent patient under the age of 80 years. The choice of procedure by the patient and the surgeon should be determined by the realisation that the use of internal fixation is associated with a $\mathbf{3 0 \%}$ risk of failure requiring further surgery. If this is accepted, however, hemiarthroplasty is avoided, which, in our study has a significantly

J. N. S. Davison, FRCS (Tr \& Orth), Consultant Orthopaedic Surgeon Leicester Royal Infirmary, Infirmary Square, Leicester LE1 5WW, UK

S. J. Calder, MD, FRCS Orth, Consultant Orthopaedic Surgeon Leeds General Infirmary, Great George Street, Leeds LS1 3EX, UK.

G. H. Anderson, FRCS Orth, Consultant Orthopaedic Surgeon Derriford Hospital, Derriford, Plymouth PL6 8DH, UK.

G. Ward, MPhil, SROT, Occupational Therapist, Senior Lecturer in Occupational Therapy

School of Health and Social Sciences, Coventry University, Priory Street, Coventry CV1 5FB, UK.

C. Jagger, MD, Professor

Department of Public Health and Epidemiology

W. M. Harper, MD, FRCS Ed, Professor

Department of Orthopaedic Trauma

University of Leicester, Leicester LE1 7RH, UK.

P. J. Gregg, MD, FRCS, Professor

Department of Orthopaedics, University of Newcastle upon Tyne, Newcastle upon Tyne, UK.

Correspondence should be sent to Mr J. N. S. Davison.

(C)2001 British Editorial Society of Bone and Joint Surgery 0301-620X/01/211128\$2.00 shorter mean survival time. The use of a bipolar prosthesis has no significant advantage.

J Bone Joint Surg [Br] 2001;83-B:206-12.

Received 8 March 2000; Accepted after revision 24 July 2000

The choice of surgical treatment for a displaced intracapsular fracture of the proximal femur in the elderly remains as controversial now as it was almost 50 years ago when Speed ${ }^{1}$ referred to it as "the unsolved fracture".

Our study was designed to compare the outcome after internal fixation, unipolar hemiarthroplasty and bipolar hemiarthroplasty, with particular reference to mortality and surgical morbidity, the rate of reintervention, functional recovery, level of dependency and subjective outcome. Few prospective, randomised trials have been performed which evaluate alternative treatments for displaced fractures of the femoral neck, ${ }^{2}$ and to the best of our knowledge no such comparison of these three treatments has been reported.

\section{Patients and Methods}

All patients with a displaced intracapsular fracture of the proximal femur and aged between 65 and 79 years were considered for entry into the study. The patients were assessed by a research fellow, who recorded full details of health, mobility and dependency before the fracture occurred. We excluded patients who had a mental test score of less than 5/13 (Table I), uncontrolled Parkinson's disease, a pathological fracture or disseminated malignancy, Paget's disease, rheumatoid arthritis or were on long-term steroid therapy .

Patients were assigned by computer generation of random numbers to one of three treatments: 1) reduction and internal fixation using an 'Ambi' compression hip screw (AHS) and a two-hole plate (Smith \& Nephew Richards, Cambridge, UK); 2) a cemented Thompson unipolar hemiarthroplasty (Corin Medical Ltd, Cirencester, UK); or 3) a cemented Monk (hard-top) bipolar hemiarthroplasty (Johnson \& Johnson Orthopaedics, Bracknell, UK).

Between January 1, 1991 and January 31, 1996, 280 patients were recruited. There were 93 in the internal fixation group, 90 in the Thompson group and 97 in the Monk group. 
Table I. Abbreviated mental test score ${ }^{3}$

\begin{tabular}{ll}
\hline One point is given for each correct response. & \\
Maximum score $=13$ & \\
An address is given to the subject who is then instructed & \\
to memorise it (e.g. 42, West Street, Barkminster). & \\
Age in years & 1 \\
Time of day, to nearest hour & 1 \\
Current year & 1 \\
Name of the hospital & 1 \\
Recognition of 2 people & 1 \\
Date of birth: & \\
$\quad$ Day & 1 \\
Month & 1 \\
Year & 1 \\
Dates of World War II & 1 \\
Name of current monarch & 1 \\
Countdown from 10 to 1 & 1 \\
Address: & 1 \\
Partially recalled & 1 \\
\hline
\end{tabular}

\section{Operative technique}

Internal fixation. The patient was positioned on the fracture table, and manipulative reduction was carried out under fluoroscopic control. After reduction, true posteroanterior and lateral radiographs were retained for formal measurement according to the criteria of Garden's index. ${ }^{4}$ A central guide-wire and one or two peripheral derotation wires were passed across the fracture to stabilise the reduction during fixation. A sliding lag screw and a $135^{\circ}$ twohole plate were used without a supplementary derotation screw. Further radiographs were obtained on completion of fixation.

Hemiarthroplasty. Replacement of the femoral head was carried out using a lateral (Hardinge) approach. The unipolar and bipolar prostheses had identical collar-and-stem profiles, and the surgical technique for implantation was the same. Methylmethacrylate cement of normal viscosity was inserted using a simple orthograde technique, with a vent and no cement restrictor.

All patients were mobilised after the operation bearing weight without restriction on the injured limb, under the direction of a physiotherapist.

All patients were invited to attend for assessment six weeks after surgery and annually for five years. Fractures which had been fixed internally were reviewed at intervals until they had united clinically and radiologically. At each attendance a verbally-conducted assessment questionnaire, which included subjective questions of function relative to the status before fracture and the level of satisfaction, was completed, as well as a formal Harris hip score.

Radiographs of the hip and pelvis were obtained at each attendance. Fractures which had been internally fixed were assessed for union, migration and cut-out of the screw, avascular necrosis and collapse, and degeneration of the joint. The pelvic radiograph was also assessed for evidence of acetabular erosion. ${ }^{5}$ This was considered to have occurred if the prosthetic head had migrated by more than $3 \mathrm{~mm}$ in a medial or superior direction on serial radiographs. The radiographs of the patients with a hemiarthroplasty were also assessed for evidence of loosening and subsidence. ${ }^{6}$

From November 1994, a home assessment was carried out annually by a research occupational therapist who was blind to the patient's operative treatment. Data were collected by interview and direct observation. The level of mobility and dependency was assessed using the Barthel index ${ }^{7}$ which is a score based on activities of daily living (Table II).

Statistical analysis. The time to death, time to revision, time of return to the preinjury state and satisfaction were compared among the three groups by proportional hazards regression models. Time to revision and death were censored on July 1, 1997. For time of return to preinjury state and satisfaction, subjects with no review who were not known to have died were excluded from the analysis.

The minimum follow-up for all 280 subjects was two years. A maximum of 233 patients was eligible for threeyear assessment, 179 at four years and 117 at five years.

Outcomes measured at each clinic review (Harris hip score, pain score and satisfaction with outcome) and the functional outcomes from home assessment (Barthel score) were analysed using MLN (Multilevel Number Modelling Software, Institute of Education, 1995) to allow for the variable numbers and times between reviews and assessments. Random-effects models were fitted, with each of the outcomes in turn as the dependent variable, and the operation group (AHS, Monk, Thompson) as the independent variable.

\section{Results}

The baseline details of the three operative groups were similar, although the AHS group was younger and more functionally independent before the fracture (Table III). All patients were Caucasian.

Initial surgery. Closed reduction was performed in all patients in the AHS group. In ten the reduction did not meet Garden's radiological criteria but was accepted. Of these, seven subsequently had a salvage procedure. An initially good reduction was lost in one patient during internal fixation and was revised to a hemiarthroplasty. Satisfactory reduction and fixation were achieved in the remaining patients. No surgical problems were encountered during any of the hemiarthroplasty procedures.

Mortality. Significant differences in survival were found among the three groups, with the mean survival time for the AHS group being 79 months compared with 61 months and 68 months in the Thompson and Monk groups, respectively (Wald chi-square $=9.58$ on $2 \mathrm{df}, \mathrm{p}=0.008$ ). The differences in early mortality to six months are shown in Figure 1a. The proportion surviving to various time points from the date of operation are shown in Table IV and Figure 1b by operative group. 
Table II. The modified Barthel index ${ }^{7}$ based on the activities of daily living

\begin{tabular}{|c|c|}
\hline Bowels & $\begin{array}{l}0 \text {, incontinent } \\
1 \text {, occasional accident (maximum } 1 \text { per week) } \\
2 \text {, continent }\end{array}$ \\
\hline Bladder & $\begin{array}{l}0 \text {, incontinent, or catheterised } \\
1 \text {, occasional accident (maximum } 1 \text { per day) } \\
2 \text {, continent }\end{array}$ \\
\hline Grooming & $\begin{array}{l}0, \text { needs help with personal care } \\
1 \text {, independent }\end{array}$ \\
\hline Toilet use & $\begin{array}{l}0, \text { dependent } \\
1 \text {, requires some help } \\
2 \text {, independent }\end{array}$ \\
\hline Feeding & $\begin{array}{l}0, \text { unable } \\
1 \text {, requires some help } \\
2 \text {, independent }\end{array}$ \\
\hline Transfer (bed to chair) & $\begin{array}{l}0 \text {, unable, no sitting balance } \\
1 \text {, requires major physical help, able to sit } \\
2 \text {, requires supervision or some minor physical help } \\
3 \text {, independent }\end{array}$ \\
\hline Mobility & $\begin{array}{l}0 \text {, immobile } \\
1 \text {, wheelchair independent (including corners) } \\
2 \text {, walks with assistance or supervision of one person } \\
3 \text {, independent (but may use any walking aid) }\end{array}$ \\
\hline Dressing & $\begin{array}{l}0 \text {, dependent } \\
1 \text {, requires some help } \\
2, \text { independent }\end{array}$ \\
\hline Stairs & $\begin{array}{l}0, \text { unable } \\
1 \text {, needs help (verbal, physical, carrying aid) } \\
2, \text { independent }\end{array}$ \\
\hline Bathing & $\begin{array}{l}0 \text {, dependent } \\
1 \text {, independent (or uses shower) }\end{array}$ \\
\hline
\end{tabular}

Table III. Details of the patients by operation group, by number and percentage

\begin{tabular}{|c|c|c|c|}
\hline & $\begin{array}{l}\text { AHS } \\
(\mathbf{n}=93)\end{array}$ & $\begin{array}{l}\text { Thompson } \\
(\mathrm{n}=90)\end{array}$ & $\begin{array}{l}\text { Monk } \\
(\mathbf{n}=97)\end{array}$ \\
\hline Female & $70(75.3)$ & $71(78.9)$ & $72(74.2)$ \\
\hline Independent of aids & $67(72.0)$ & $55(61.1)$ & $66(68.0)$ \\
\hline Independent in mobility & $79(85.0)$ & $69(76.7)$ & $74(76.3)$ \\
\hline Incontinent & $1(1.1)$ & $8(8.9)$ & $1(1.1)$ \\
\hline $\begin{array}{l}\text { Marital status } \\
\text { Single } \\
\text { Married } \\
\text { Widowed/Divorced }\end{array}$ & $\begin{aligned} 9 & (9.7) \\
45 & (48.4) \\
39 & (41.9)\end{aligned}$ & $\begin{array}{r}9(10.0) \\
45(50.0) \\
36(40.0)\end{array}$ & $\begin{array}{l}10(10.3) \\
47(48.5) \\
40(41.2)\end{array}$ \\
\hline Living independently in the community & $87(93.6)$ & $83(92.2)$ & $91(93.8)$ \\
\hline With any previous fracture & $18(23.1)$ & $25(28.8)$ & $28(31.1)$ \\
\hline Median age (years $\left.\left(\mathrm{IQR}^{*}\right)\right)$ & 73 (70 to 77$)$ & $76(72$ to 77$)$ & 75 (71 to 78$)$ \\
\hline $\begin{array}{l}\text { Median delay between fracture } \\
\text { and admission (days (IQR)) }\end{array}$ & $0(0$ to 0$)$ & $0(0$ to 0$)$ & $0(0$ to 1$)$ \\
\hline $\begin{array}{l}\text { Median delay between } \\
\text { admission and operation (days (IQR)) }\end{array}$ & $2(1$ to 2$)$ & $2(1$ to 3$)$ & $2(1$ to 3$)$ \\
\hline Median inpatient stay (days (IQR)) & $14(10$ to 21$)$ & 15 (11 to 22$)$ & 15 (13 to 21$)$ \\
\hline Median mental test score (IQR) & $13(13$ to 13$)$ & $13(13$ to 13$)$ & 13 (12 to 13$)$ \\
\hline
\end{tabular}

$*$ interquartile range 
Table IV. Proportion surviving and proportion revision-free at various times after operation with $95 \%$ confidence intervals in parentheses

\begin{tabular}{|c|c|c|c|c|c|c|}
\hline \multirow{2}{*}{$\begin{array}{l}\text { Time from operation } \\
\text { (mth) }\end{array}$} & \multicolumn{3}{|l|}{ Survival (\%) } & \multicolumn{3}{|c|}{ Revision-free (\%) } \\
\hline & AHS & Monk & Thompson & AHS & Monk & Thompson \\
\hline 0 & 100 & 100 & 100 & 100 & 100 & 100 \\
\hline 6 & 95 (90 to 99$)$ & 90 (84 to 96$)$ & 93 (88 to 98$)$ & $82(75$ to 90$)$ & $99(97$ to 100$)$ & 99 (97 to 100$)$ \\
\hline 12 & 91 (86 to 97$)$ & 88 (81 to 94$)$ & $89(82$ to 95$)$ & 79 (71 to 87$)$ & 99 (97 to 100$)$ & 99 (97 to 100$)$ \\
\hline 18 & $89(83$ to 96$)$ & 86 (79 to 93$)$ & 86 (78 to 93$)$ & 76 (67 to 84$)$ & 99 (97 to 100$)$ & 99 (97 to 100$)$ \\
\hline 24 & $88(81$ to 95$)$ & 83 (76 to 91$)$ & 80 (71 to 88$)$ & 73 (64 to 82$)$ & $98(94$ to 100$)$ & 99 (97 to 100$)$ \\
\hline 30 & $83(75$ to 91$)$ & 81 (73 to 89$)$ & 75 (66 to 84$)$ & 73 (64 to 82$)$ & $98(94$ to 100$)$ & 99 (97 to 100$)$ \\
\hline 36 & $81(73$ to 90$)$ & 78 (70 to 87$)$ & 72 (63 to 82$)$ & $71(61$ to 81$)$ & $98(94$ to 100$)$ & $99(97$ to 100$)$ \\
\hline
\end{tabular}

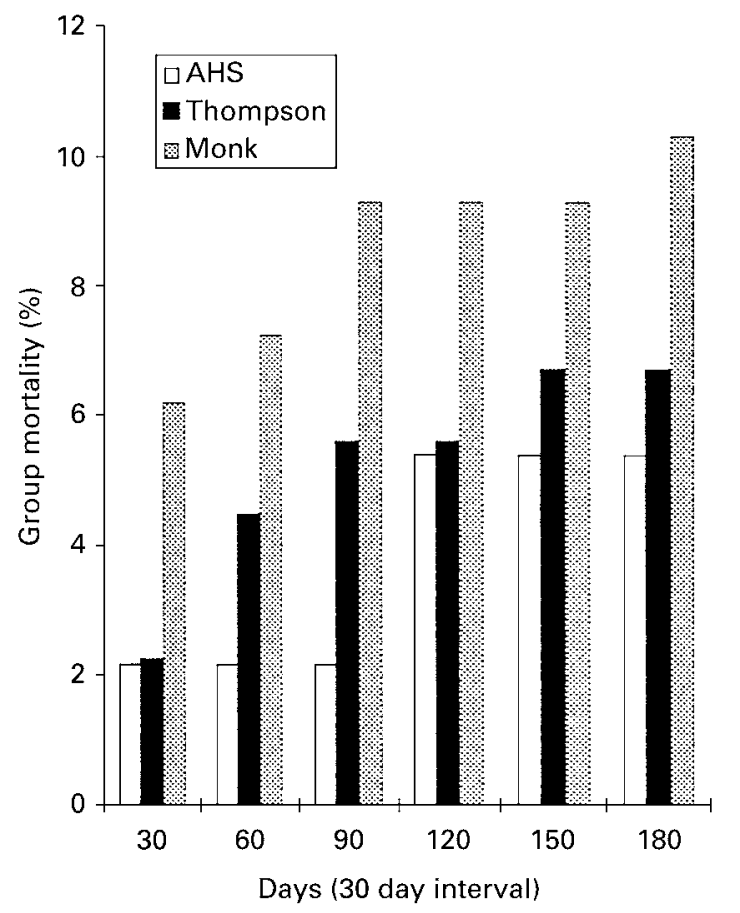

Fig. 1a

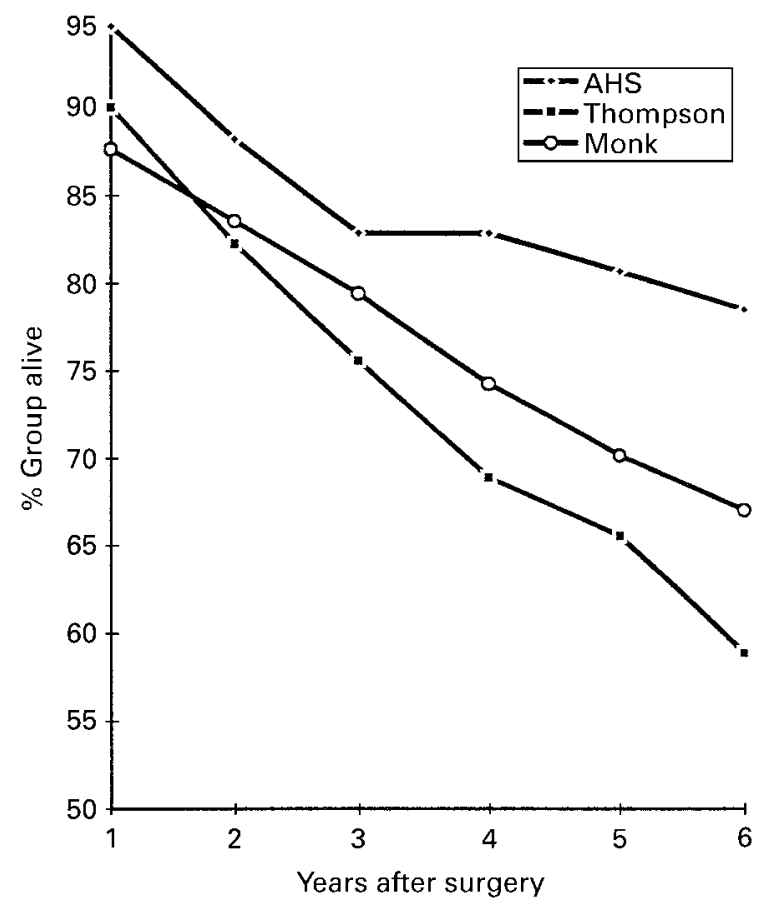

Fig. 1b

Figure 1a - Bar chart showing cumulative mortality over first 180 days after surgery by group. Figure $1 \mathrm{~b}-$ Graph showing percentage survival over time after surgery.

Morbidity and revision surgery. Table $\mathrm{V}$ summarises the surgical complications and outcomes encountered in all three groups. The rates of revision for the three groups were substantially different, with 28 revision procedures being required in the AHS group compared with three in the Thompson group and five in the Monk group (Wald chisquare $=25.9$ on $2 \mathrm{df}, \mathrm{p}<0.0001$ ).

Internal fixation. There was a high incidence of failure of fixation and rate of reoperation after internal fixation (Tables IV and V). The rate of surgical complications was 21 of $93(22.6 \%)$ at one year, and 19 of 93 patients (20.4\%) had had a salvage arthroplasty procedure within one year for symptomatic failure of fixation. At two years, complications had occurred in 27 of 93 patients (29\%), 21 (78\%) resulting from the lag screw cutting out or penetrating the femoral head. At two years, 25 patients $(26.8 \%)$ had been revised. Overall, 28 patients $(30.1 \%)$ in the internal fixation group required salvage surgery. Local complications occurred in 32 of 93 patients (34.4\%).

Thompson hemiarthroplasty. There were no deep wound infections and the rate of dislocation was $1.1 \%$. Two patients developed pain, with radiological evidence of acetabular erosion. In one, cement debris was identified within the acetabulum and total hip arthroplasty was performed at five months. The second patient required revision after three years. The surgical intervention rate was 3.3\% in this group.

Monk hemiarthroplasty. Five patients (5.2\%) have undergone revision surgery. One patient developed a deep wound infection (1\%) and dislocation occurred in two (2.1\%). One patient with persistent trochanteric pain had an exploration and excision of heterotopic bone after 18 months. The symptoms persisted but revision surgery was declined. One Monk prosthesis was revised at four years for persistent 
Table V. Summary of complications by trial group over time

\begin{tabular}{|c|c|c|c|}
\hline Number & $\begin{array}{l}\text { Days afte } \\
\text { surgery }\end{array}$ & Complication/outcome & Revision procedure \\
\hline \multicolumn{4}{|c|}{ Internal fixation } \\
\hline 138 & 9 & Fixation failure; lag screw cut-out & THR \\
\hline 371 & 16 & Fixation failure; lag screw cut-out & Hemiarthroplasty \\
\hline 121 & 17 & Fixation failure; lag screw cut-out & THR \\
\hline 66 & 20 & Early lag screw penetration. No intervention; ambulant and pain-free to 5 yrs in nursing home & Nil \\
\hline 482 & 21 & Wound infection 3 weeks after surgery; chronic discharge & Nil \\
\hline 312 & 23 & Fixation failure; lag screw cut-out after fall onto the hip & Hemiarthroplasty \\
\hline 585 & 34 & Fixation failure; lag screw cut-out & THR \\
\hline 294 & 45 & Fixation failure; lag screw cut-out & Hemiarthroplasty \\
\hline 608 & 45 & Fixation failure; lag screw cut-out & Hemiarthroplasty \\
\hline 634 & 62 & Fixation failure; lag screw cut-out & Hemiarthroplasty \\
\hline 466 & 63 & Fixation failure; lag screw cut-out. THR complicated by recurrent dislocation & THR \\
\hline 298 & 69 & Avascular necrosis and collapse with lag screw cut-out & THR \\
\hline 217 & 75 & Fixation failure; lag screw cut-out & THR \\
\hline 305 & 82 & Avascular segmental collapse & THR \\
\hline 46 & 96 & Fixation failure; lag screw cut-out & THR \\
\hline 354 & 107 & Fixation failure; lag screw cut-out & THR \\
\hline 29 & 107 & Fixation failure; lag screw cut-out. 1 st revision to Thompson, 2 nd to THR at $4 \mathrm{yrs}$ & Hemiarthroplasty, THR \\
\hline 264 & 110 & Fixation failure; lag screw cut-out & THR \\
\hline 296 & 193 & Nonunion with avascular collapse & THR \\
\hline 315 & 204 & Avascular segmental collapse and lag screw cut-out & THR \\
\hline 274 & 259 & Symptomatic nonunion & THR \\
\hline 685 & 393 & Nonunion with screw penetration & Removal of fixation \\
\hline 453 & 498 & Nonunion with screw penetration & THR \\
\hline 68 & 536 & Avascular necrosis & THR \\
\hline 235 & 575 & Nonunion with avascular collapse and cut-out & THR \\
\hline 67 & 581 & Avascular necrosis & THR \\
\hline 251 & 696 & Nonunion with screw penetration & THR \\
\hline 190 & 1790 & Avascular necrosis with advanced arthritis & THR \\
\hline 256 & 670 & Established nonunion, asymptomatic & Nil \\
\hline 309 & 1084 & Avascular necrosis with arthritis, mild symptoms & Nil \\
\hline 160 & 1037 & Avascular necrosis. Removal of fixation, followed after 2 yrs by THR & Removal of fixation, THR \\
\hline 194 & 1265 & Nonunion with screw penetration & Removal of fixation \\
\hline \multicolumn{4}{|c|}{ Thompson hemiarthroplasty } \\
\hline 554 & 1 & Dislocation $\times 2$ & Closed reduction \\
\hline 290 & 165 & Acetabular erosion & THR \\
\hline 493 & 1226 & Acetabular erosion & THR \\
\hline \multicolumn{4}{|c|}{ Monk hemiarthroplasty } \\
\hline 640 & 3 & Dislocation. Recurrent pneumonia and died & Closed reduction \\
\hline 433 & 15 & Dislocation & Open reduction \\
\hline 544 & 550 & Refractory pain; heterotopic bone & Open biopsy and bone excision \\
\hline 161 & 1263 & Deep infection, chronic recurrent discharging sinus & Excision arthroplasty \\
\hline 304 & 1460 & Acetabular erosion & THR \\
\hline
\end{tabular}

groin pain. The origin of the pain was not established but it resolved after total hip arthroplasty.

Clinical review. The patients seen for review are summarised in Table VI. The three groups were similar in the proportions which had clinic reviews and home assessments. The baseline characteristics of those patients complying with the clinic and home reviews were similar among the three groups.

Return to preinjury state. The mean time of return to the preinjury state for those receiving the Monk hemiarthroplasty was 24 months compared with 36 months in the AHS and Thompson groups. Two years after the operation, $51 \%$ of the Monk group had not returned to the preinjury state compared with $74 \%$ of the AHS patients and $71 \%$ of the Thompson group (Table VII).

These differences did not reach significance (Wald chisquare $=4.09$ on $2 \mathrm{df}, \mathrm{p}=0.09$ ).

Satisfaction. Significant differences in the rates of satisfac- 
Table VI. Number of patients reviewed (percentages in parentheses) and place of review

\begin{tabular}{lccll}
\hline & Clinic only & Clinic and home & Home only & No review \\
\hline AHS & $8(9)$ & $53(57)$ & $15(16)$ & $17(18)$ \\
Thompson & $16(18)$ & $47(52)$ & $11(12)$ & $16(18)$ \\
Monk & $11(11)$ & $59(61)$ & $10(10)$ & $17(18)$ \\
Total & $35(12.5)$ & $159(56.8)$ & $36(12.9)$ & $50(17.8)$ \\
\hline
\end{tabular}

Table VII. Percentage failing to have returned to preinjury state and percentage unsatisfied at various times after operation, with $95 \%$ confidence intervals in parentheses

\begin{tabular}{|c|c|c|c|c|c|c|}
\hline \multirow{2}{*}{$\begin{array}{l}\text { Time from operation } \\
\text { (mth) }\end{array}$} & \multicolumn{3}{|c|}{ Not having returned to preinjury state } & \multicolumn{3}{|l|}{ Unsatisfied } \\
\hline & AHS & Monk & Thompson & AHS & Monk & Thompson \\
\hline 0 & 100 & 100 & 100 & 100 & 100 & 100 \\
\hline 6 & 100 & 100 & 100 & 100 & 100 & 100 \\
\hline 12 & 88 (80 to 96$)$ & 80 (70 to 89$)$ & $90(83$ to 98$)$ & 78 (68 to 89$)$ & $59(48$ to 71$)$ & 65 (53 to 76$)$ \\
\hline 18 & $76(67$ to 88$)$ & 58 (46 to 70$)$ & 75 (64 to 87$)$ & $36(23$ to 48$)$ & $20(10$ to 28$)$ & 9 (2 to 17$)$ \\
\hline 24 & $74(62$ to 85$)$ & 53 (41 to 65$)$ & $71(59$ to 83$)$ & 30 (18 to 42$)$ & 15 (6 to 23$)$ & $6(0$ to 12$)$ \\
\hline 30 & 53 (38 to 68$)$ & 45 (33 to 58 ) & $56(41$ to 70$)$ & $19(8$ to 30$)$ & $9(2$ to 15$)$ & $3(0$ to 8$)$ \\
\hline 36 & 49 (38 to 68$)$ & 43 (31 to 56$)$ & 48 (33 to 63$)$ & $9(0$ to 19$)$ & $9(2$ to 15$)$ & $0(0$ to 0$)$ \\
\hline
\end{tabular}

Table VIII. Mean Harris hip score by group at each annual review

\begin{tabular}{|c|c|c|c|c|c|}
\hline & \multicolumn{5}{|c|}{ Annual review (year) } \\
\hline & 1 & 2 & 3 & 4 & 5 \\
\hline AHS & 70.8 & 70.7 & 70.6 & 71.8 & 70 \\
\hline Thompson & 71.1 & 70.7 & 72.4 & 68.4 & 71.8 \\
\hline Monk & 73.2 & 77.6 & 74.8 & 77.4 & 73.6 \\
\hline
\end{tabular}

tion were found among the three groups (Wald chi-square = 11.41 on $2 \mathrm{df}, \mathrm{p}=0.003)$. The level of satisfaction with recovery was lowest in the internal fixation group. By 18 months, only $9 \%$ of those receiving a Thompson prosthesis remained dissatisfied compared with $20 \%$ in the Monk group, and $36 \%$ in the internal fixation group (Table VII). Home assessments. No significant difference in the Barthel index score was found among the three groups (chi-square $=2.28$ on $2 \mathrm{df}, \mathrm{p}=0.32$ ).

Harris hip score. The mean Harris hip scores at each annual review by group are shown in Table VIII. No significant differences in score were identified among the groups.

\section{Discussion}

The age and exclusion criteria which we used led to the selection of patients in whom the choice of surgical treatment is the most controversial. Few prospective, randomised trials have been conducted for this fracture, and the large number of other reported studies often draw conclusions which conflict. ${ }^{2}$

The principal finding in this trial was the significant difference in the rate of reoperation between the internal fixation and hemiarthroplasty groups. The most common type of failure of internal fixation was redisplacement of the fracture with the lag screw cutting out of the femoral head. The sliding hip screw and plate were selected for use in our study after a prospective, randomised trial carried out in our hospital had shown similar results compared with cannulated hip screws, but without the risk of subtrochanteric fracture associated with cannulated screws. ${ }^{8}$ Some surgeons prefer alternative methods of fixation of intracapsular hip fractures. A meta-analysis of fixation methods showed that the sliding compression screw and plate performs similarly to other methods. ${ }^{9}$

The difference in reoperation and rate of revision between internal fixation and hemiarthroplasty was similar to other reports. ${ }^{10-12}$ Late failure and revision are most commonly associated with avascular necrosis and collapse of the femoral head, which is normally evident within two years of injury. All subjects in our study were assessed beyond that period.

A significantly longer mean survival in the internal fixation group seemed to conflict with the much higher rate of surgical reintervention in that group. The difference remained despite statistical correction for the slightly younger mean age and lower dependency level of the subjects randomised to this group. Previous reports noted that a transient increase in mortality after hemiarthroplasty compared with internal fixation was lost after one year. ${ }^{2}$

The number of patients who declined follow-up (outpatient or home assessment) was disappointing, although survivors who were successfully reviewed were evenly 
distributed between the three groups and were found to be representative samples of each. No significant functional differences were identified among the three groups in patients reviewed by both outpatient clinic and home assessment. Subjective assessment of outcome also demonstrated no marked difference between the groups, although the internal fixation group fared least well.

No significant benefit was demonstrated from the use of the Monk bipolar implant during the follow-up period. We believe that a patient's own assessment of outcome is important. ${ }^{13}$ While the Monk group had the highest number claiming to have returned to their preinjury functional state, this was not statistically significant, and patients in the Thompson group were the most satisfied. Both acetabular erosion and loosening in hemiarthroplasty survivors will potentially lead to further cases requiring revision. Only extended follow-up will determine the scale of these problems, and demonstrate whether the theoretical advantage of the bipolar articulation over the Thompson implant proves to be of functional benefit.

We conclude that an informed choice between internal fixation and hemiarthroplasty can be made with the individual patient. The wish to avoid the risk of symptomatic failure of fixation requiring secondary surgery (approximately $30 \%$ in this study) will lead many patients to prefer replacement of the femoral head despite the potentially higher mortality. Most patients who are happy to accept this risk and undergo internal fixation will successfully retain their femoral head, although our study failed to demonstrate any clear advantage in terms of symptoms and function by doing so.

We thank the consultant orthopaedic surgeons of Leicester Royal Infirmary for allowing patients under their care to participate in this study. We also thank the specialist registrars and all other staff who helped with the review of patients.
Although none of the authors have received or will receive benefits for personal or professional use from a commercial party related directly or indirectly to the subject of this article, benefits have been or will be received but will be directed solely to a research fund, foundation, educational institution, or other non-profit organisation with which one or more of the authors are associated.

\section{References}

1. Speed K. Fractures: 50 year review of teaching and treatment. Illinois Med J 1952;102:85-92.

2. Lu-Yao, Keker RB, Littenberg B, Wennberg JE. Outcomes after displaced fractures of the femoral neck: a meta-analysis of one hundred and six published reports. J Bone Joint Surg [Am] 1994;76-A:15-25.

3. Blessed G, Tomlinson BE, Roth M. The association between quantitative measures of dementia and senile change in the cerebral grey matter of elderly subjects. Br J Psychiatry 1968;114:797-811.

4. Garden RS. Malreduction and avascular necrosis in subcapital fractures of the femur. J Bone Joint Surg [Br] 1971;53-B:183-97.

5. Wetherell RG, Amis AA, Heatley FW. Measurement of acetabular erosion: the effect of pelvic rotation on common landmarks. $J$ Bone Joint Surg [Br] 1989;71-B:447-51.

6. Yamagata M, Chao EY, Ilstrup DM, et al. Fixed-head and bipolar hip endoprostheses: a retrospective clinical and roentgenographic study. J Arthroplasty 1987;2:327-41.

7. Collin C, Wade DT, Davies S, Horne V. The Barthel Index: a reliability study. Int J Disabil Studies 1988;10:60-63.

8. Harper WM. A prospective randomised trial comparing multiple parallel cannulated screws with a sliding hip screw and plate. Thesis (Leicester Univ.) 1996: treatment of intracapsular proximal femoral fractures.

9. Parker MJ, Blundell C. Choice of implant for internal fixation of femoral neck fractures: meta-analysis of 25 randomised trials including 4925 patients. Acta Orthop Scand 1998;69:138-43.

10. Søreide O, Mölster A, Raugstad TS. Internal fixation versus primary prosthetic replacement in acute femoral neck fractures: a prospective, randomized clinical study. Br J Surg 1979;66:56-60.

11. Sikorski JM, Barrington R. Internal fixation versus hemiarthroplasty for the displaced subcapital fracture of the femur: a prospective randomised study. J Bone Joint Surg [Br] 1981;63-B:357-61.

12. Skinner P, Riley D, Ellery J, et al. Displaced subcapital fractures of the femur: a prospective randomised comparison of internal fixation, hemiarthroplasty and total hip replacement. Injury 1989;20:291-3.

13. Calder SJ, Anderson GH, Jagger C, Harper WM, Gregg PJ. Unipolar or bipolar prosthesis for displaced intracapsular hip fracture in octogenarians: a randomised prospective study. J Bone Joint Surg [Br] 1996;78-B:391-4. 